\title{
Potential specific immunological indicators for stroke associated infection are partly modulated by sympathetic pathway activation
}

\author{
Huan Wang ${ }^{1}$, Fu-Ling Yan ${ }^{1}$, Michael Cunningham ${ }^{3}$, Qi-Wen Deng ${ }^{1}$, Lei Zuo ${ }^{1}$, Fang- \\ Lan Xing ${ }^{1}$, Lu-Hang Shi ${ }^{2}$, Shan-Shan $\mathrm{Hu}^{2}$, Ya Huang ${ }^{2}$ \\ ${ }^{1}$ Neurologic Department, Affiliated Zhongda Hospital, School of Medicine, Southeast University, Nanjing, China \\ ${ }^{2}$ School of Medicine, Southeast University, Nanjing, China \\ ${ }^{3}$ Public Health School of Southeast University, Nanjing, China \\ Correspondence to: Fu-Ling Yan, email: yanfuling218@163.com \\ Keywords: stroke, infection, immune, sympathetic pathway, HLA-DR \\ Received: February 25, $2016 \quad$ Accepted: June 30, $2016 \quad$ Published: July 08, 2016
}

\section{ABSTRACT}

Background: Evidence has led to the consideration of immunodepression after stroke as an important contributor to stroke associated infection (SAI). However, so far no specific immunological indicator has been identified for SAI, and the underlying mechanism remains poorly understood.

Results: SAI patients had significantly higher IL-6 and IL-10 levels and lower HLA-DR levels than no-infection patients within $48 \mathrm{~h}$ after stroke onset. NA significantly increased IL-10 levels, reduced HLA-DR expression, and decreased IL- 6 expression by increasing $\beta$-arrestin 2 expression which reduced the activation of the NF-KB pathway. Propranolol reversed this effect of NA by reducing $\beta$-arrestin 2 expression.

Materials and Methods: A systematic search for eligible clinical studies was applied to pool the differences in peripheral cytokine levels between infection and no-infection stroke patients. The underlying mechanism behind these differences was investigated in vitro by applying norepinephrine (NA) and lipopolysaccharide (LPS) to simulate sympathetic pathway activation and sepsis respectively in THP-1 cells. Propranolol was applied to determine the effect of reversing the activation of the sympathetic pathway. Immunological indicators were also detected to assess the immune activation of THP-1 cells and measurements of the expression of $\beta$-arrestin 2 , NF-KB, IKBa and phosphor-IKBa were performed to assess the activation of the sympathetic pathway.

Conclusion: IL-6, IL-10 and HLA-DR are good candidate biomarkers for SAI. The activation of the sympathetic pathway could partly account for the specific immunological alterations found in SAI patients including HLA-DR decrease and IL-10 increase, which both could be reversed by propranolol. However, the mechanism underlying IL-6 increase still needs further exploration.

\section{INTRODUCTION}

Stroke associated infections (SAI) have been generally accepted to accompany the acute phase of stroke with an incidence rate of nearly $30-60 \%$, contributing to a poor prognosis and higher mortality in stroke patients [1-3]. Early diagnosis with biomarker(s) as well as targeted treatments is the most effective approaches to avoid these concerns. However, there is still no effective biomarker(s) to predict SAI. Moreover, none of the management strategies, such as prophylactic antibiotic treatment or aspiration prevention, have proven effective for SAI reduction in the clinic [4-5]. Therefore, it is essential to explore its pathogenesis in order to find an effective biomarker(s).

Numerous studies have shown that a profound stroke-triggered immunodepression with significant changes in the levels of inflammatory factors leads to serious infectious complications in stroke patients [6-7]. Both clinical and animal studies show that a multitude of cytokines such as IL-6 and IL-10 are activated after 
stroke, induce stroke-associated immunodepression, and greatly increase the risk of infection [8-11]. Furthermore, there is increasing evidence that reduced monocytic human leukocyte antigen (HLA-DR) expression can independently predict the occurrence of SAI. Even though it is generally accepted that nuclear factor kappa B (NF$\kappa \mathrm{B})$ activates the expression of various immunological factors, the mechanism underlying their expression after stroke still remains poorly understood [12-13].

Experimental evidence suggests that the sympathetic pathway is hyperactivated after stroke, which results inimmunodeficiency and an increased susceptibility to SAI [6, 14-15]. Xabier's and Chamorro's clinical studies joined this consensus with their discovery of a strong positive correlation between SAI risk and metanephrine levels [16-17]. Importantly, $\beta$-arrestin2, a major molecule in G-protein-coupled receptor signaling and the sympathetic nervous system regulation of the immune system, is able to inhibit $\mathrm{NF}-\kappa \mathrm{B}$ activation by directly interacting with $\mathrm{I} \kappa \mathrm{B} \alpha$ [18-19]. NF- $\kappa \mathrm{B}$ sequestration also occurs after associating with $\mathrm{I} \kappa \mathrm{B} \alpha$ under normal conditions [20]. These findings suggest that the activation of the sympathetic $\beta$-arrestin $2 / \mathrm{I} \kappa \mathrm{B} \alpha / \mathrm{NF}-\kappa \mathrm{B}$ pathway might contribute to the increase in expression of immunological factors after stroke.

Hence the purpose of this study was to investigate the specific immunological indicator(s) for SAI and to determine if their expression is promoted by activation of the sympathetic pathway. Furthermore, propranolol, a nonselective beta-blocker, was applied to inhibit the sympathetic pathway activation in order to confirm that the observed effects were due to the sympathetic pathway [21-22].

\section{RESULTS}

\section{Peripheral cytokines levels were significantly increased in SAI patients}

After a study selection process (Supplemental Data, Supplementary Figure S1), ten articles involving 613 patients were identified for the pooled analyses. The general characteristics of these studies are summarized in Table 1. SAI patients had significantly higher IL-6 (Std. MD 2.35; 95\%CI 0.82-3.89; $\mathrm{P}=0.003$ ) and IL-10 (Std.MD $1.08 ; 95 \%$ CI $0.09-2.06 ; \mathrm{P}=0.03$ ) levels compared to stroke patients without infection within $48 \mathrm{~h}$ after stroke onset (Figure 1a-b). Moreover, significantly lower HLA-DR levels (Std.MD $-0.93 ; 95 \%$ CI $-1.35-0.51 ; \mathrm{P}<0.0001$ ) were found in SAI patients (Figure 1c). However, neither TNF- $\alpha$ (Std.MD -0.02; 95\%CI $-0.50-0.47 ; \mathrm{P}=0.94)$ nor IFN- $\gamma($ Std.MD $-0.21 ; 95 \% \mathrm{CI}-0.67-0.24 ; \mathrm{P}=0.36)$ differences were statistically significant (Figure 1d-e). Detailed results of these pooled analyses are further presented in the Supplemental Data.

\section{Sympathetic neurotransmitter depresses the cytokine levels in THP-1 cells induced by LPS}

Compared to THP-1 cells treated with LPS alone, co-treatment with LPS and NA led to a dose-dependent decrease in pro-inflammatory cytokines, with significant decreases in IL-6, IL-8, TNF- $\alpha$ and IL-1 $\beta$ (Figure 2). Interestingly, IL-10, an anti-inflammatory cytokine, was not significantly increased by treatment with LPS and NA. And, NA alone could not significantly increase cytokine release in THP-1 cells (Supplemental Data, Supplementary Figure S2).

In this study there was concern that the ELISA kit might not have sufficient sensitivity to detect IL-10. Although some clinical and animal studies detected IL-10 with ELISA analysis, the levels were much lower than that of other cytokines. For this reason, RT-PCR was applied to detect cytokine expression in the following section.

\section{Propranolol reverses the immune suppression induced by sympathetic neurotransmitters in THP-1 cells}

Considering that the expression levels for each cytokine were strikingly decreased when the cells were treated with NA at the concentrations of $100 \mu \mathrm{M}$ and LPS $(\mathrm{P}<0.01)$ (Figure 2), we performed the following experiments using NA at the concentrations of $100 \mu \mathrm{M}$. As shown in Figure 3, compared to the LPS stimulation group (IL-6: $492.26 \pm 35.96 \mathrm{pg} / \mathrm{ml}$, TNF- $\alpha: 1374.56 \pm 42.70 \mathrm{pg} /$ $\mathrm{ml}$, IL-1 $\beta$ : $342.45 \pm 9.55 \mathrm{pg} / \mathrm{ml}$, IL-8: $2292.95 \pm 33.35 \mathrm{pg} /$ $\mathrm{ml}$ ), NA co-stimulation significantly inhibited proinflammatory cytokines levels induced by LPS in THP1 cells, including IL-6 (322.11 $\pm 7.49 \mathrm{pg} / \mathrm{ml}), \mathrm{TNF}-\alpha$ $(1181.55 \pm 27.91 \mathrm{pg} / \mathrm{ml}), \mathrm{IL}-1 \beta(237.60 \pm 2.73 \mathrm{pg} / \mathrm{ml})$ and IL-8 $(1745.88 \pm 48.84 \mathrm{pg} / \mathrm{ml})$. However, in the presence of propranolol, these cytokine levels climbed substantially (IL-6: $473.83 \pm 38.83 \mathrm{pg} / \mathrm{ml}, \mathrm{TNF}-\alpha$ : $1261.56 \pm 37.53 \mathrm{pg} / \mathrm{ml}$, IL-1 $\beta: 322.32 \pm 10.02 \mathrm{pg} / \mathrm{ml}$ and IL-8: $2272.36 \pm 26.32 \mathrm{pg} /$ $\mathrm{ml})$. For each cytokine level, the difference between the propranolol group and the NA and LPS co-treatment group was statistically significant $(\mathrm{P}<0.01, \mathrm{P}<0.05, \mathrm{P}<0.01$, $\mathrm{P}<0.01)$.

The RT-PCR results were consistent with the ELISA analysis showing significantly higher expression of IL- 6 , TNF- $\alpha$, IL- $1 \beta$ and IL- 8 gene in the propranolol stimulation group compared to the LPS and NA costimulation group $(\mathrm{P}<0.01, \mathrm{P}<0.01, \mathrm{P}<0.05, \mathrm{P}<0.01)$ (Figure $4 \mathrm{a}-\mathrm{d}$ ). Moreover, as shown in Figure $4 \mathrm{e}$, an increase of IL-10 was detected in the LPS and NA costimulation group $(0.01 \pm 0.001)$, which was significantly different from IL-10 gene expression in the LPS group $(\mathrm{P}<0.01)$. And this expression increase in the LPS and NA co-stimulation group was significantly inhibited by propranolol $(0.007 \pm 0.001, \mathrm{P}<0.01$, Figure $4 \mathrm{e})$. 
Table 1: Characteristics of included studies

\begin{tabular}{|c|c|c|c|c|c|c|c|c|}
\hline \multirow[t]{2}{*}{ First Author } & \multirow[t]{2}{*}{ Publish Year } & \multirow{2}{*}{$\begin{array}{c}\text { Study } \\
\text { Location }\end{array}$} & \multicolumn{2}{|c|}{ Stroke Patients } & \multirow{2}{*}{$\begin{array}{l}\text { Evaluation } \\
\text { Indexes }\end{array}$} & \multirow{2}{*}{$\begin{array}{l}\text { Time of Blood } \\
\text { Collection }\end{array}$} & \multirow{2}{*}{$\begin{array}{l}\text { Type of } \\
\text { Article }\end{array}$} & \multirow{2}{*}{$\begin{array}{c}\text { Quality } \\
\text { Score }\end{array}$} \\
\hline & & & Infection & No-infection & & & & \\
\hline Chamorro [16] & 2007 & $\mathrm{C}$ & 13 & 62 & $\begin{array}{l}\text { TNF- } \alpha \\
\text { IL-10 }\end{array}$ & Day1 & $\mathrm{RCT}$ & 4 \\
\hline Haeusler [23] & 2008 & $\mathrm{C}$ & 11 & 29 & $\begin{array}{l}\text { IL-6, } \\
\text { IFN- } \gamma\end{array}$ & Day 1 & Pro & 6 \\
\hline Urra [17] & 2009 & $\mathrm{C}$ & 14 & 45 & $\begin{array}{c}\text { IFN- } \gamma, \\
\text { TNF- } \alpha, \\
\text { IL-10 }\end{array}$ & Day1 & Pro & 5 \\
\hline Hug [37] & 2009 & $\mathrm{C}$ & 25 & 25 & HLA-DR & Day1 & Pro & 7 \\
\hline Harms [38] & 2008 & $\mathrm{C}$ & 13 & 18 & HLA-DR & Day1 & $\mathrm{RCT}$ & 4 \\
\hline Warterberg [39] & 2011 & $\mathrm{C}$ & 39 & 55 & IL-6 & Day1 & Pro & 6 \\
\hline Haeusler [13] & 2012 & $\mathrm{C}$ & 6 & 14 & $\begin{array}{l}\text { IL-6,TNF- } \\
\alpha, \mathrm{HLA}-\mathrm{DR}\end{array}$ & Day1 & Pro & 7 \\
\hline Zhang [40] & 2013 & A & 32 & 74 & IL-6 & Day1 & Retro & 4 \\
\hline Kwan [8] & 2013 & $\mathrm{C}$ & 45 & 37 & $\begin{array}{l}\text { IL-6, } \\
\text { TNF- } \alpha\end{array}$ & First $48 \mathrm{~h}$ & Pro & 7 \\
\hline Worthmann [11] & 2015 & $\mathrm{C}$ & 20 & 36 & IL-6, IL-10 & Day1 & Pro & 7 \\
\hline
\end{tabular}

The quality of randomized studies was assessed by using the Jadad Scale with 0-3 (low quality) and 4-5 (high quality). The quality of nonrandomized studies was assessed by using the Newcastle-Ottawa Scale (NOS) with 0-5 (low quality) and 6-9 (high quality). C: Caucasian; A: Asian; Pro: prospective; Retro: retrospective.

The expression of HLA-DR in the LPS group $(55.26 \% \pm 4.71 \%$, Figure $5 \mathrm{~b})$ was significantly higher than in the LPS and NA co-stimulation group $(34.83 \% \pm 3.31 \%$, $\mathrm{P}<0.01$, Figure 5d,f). And, propranolol was able to antagonize the suppression effect of NA on HLA-DR expression $(54.90 \% \pm 4.93 \%$, Figure $5 \mathrm{e})$. The difference between HLA-DR expression in the propranolol group and the LPS and NA co-treatment group was statistically significant $(\mathrm{P}<0.01$, Figure $5 f)$.

\section{Norepinephrine activates the signaling pathway

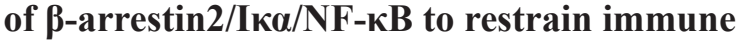 responses}

We further investigated the expression of NF- $\kappa \mathrm{B}$, I $\kappa \mathrm{B} \alpha$ and $\beta$-arrestin 2 . As shown in Figure 6 , the $N F-\kappa B$ pathway was activated by LPS resulting in increased

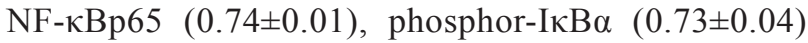
and decreased $\mathrm{I} \kappa \mathrm{B} \alpha(0.51 \pm 0.05)$. In the LPS and NA co-stimulation group $\beta$-arrestin2 was significantly increased compared to the LPS group $(0.42 \pm 0.03$, $\mathrm{P}<0.01$ ), while $\mathrm{NF}-\kappa \mathrm{B}$ p 65 and phosphor-I $\kappa \mathrm{B} \alpha$ were decreased $(0.21 \pm 0.06, \mathrm{P}<0.01 ; 0.32 \pm 0.03, \mathrm{P}<0.01)$, and expression of $\mathrm{I} \kappa \mathrm{B} \alpha$ was increased $(0.73 \pm 0.05$, $\mathrm{P}<0.05$ ). Propranolol dramatically inhibited $\beta$-arrestin2 activation by NA and LPS co-stimulation $(0.25 \pm 0.06$, $\mathrm{P}<0.01)$, resulting in increased expression of $\mathrm{NF}-\kappa \mathrm{B}$ p65 $(0.71 \pm 0.09, \mathrm{P}<0.01)$ and phospho-I $\kappa \mathrm{B} \alpha(0.72 \pm 0.07$, $\mathrm{P}<0.01)$.

In contrast to the western blot results for the phosphorylated proteins, PCR analysis did not show a significant difference in the NF- $\kappa B$ and $\mathrm{I} \kappa \mathrm{B} \alpha$ gene levels (Figure 4f,g) between any of the groups. However, $\beta$-arrestin 2 gene expression was conspicuously increased by stimulation with NA (Figure 4h). Compared to the LPS and NA co-stimulation group $(0.35 \pm 0.02), \beta$-arrestin 2 gene expression was prominently reduced in the propranolol stimulation group $(0.21 \pm 0.01, \mathrm{P}<0.01)$.

\section{DISCUSSION}

A growing body of evidence suggests that the immunodepression and immunological alteration preceding SAI after stroke might explain the high incidence of infection in these patients [15]. The identification of specific immunological indicators for predicting SAI remains contentious, even though multiple inflammatory factors have been proposed as possible candidates. Our pooled analysis confirms that 
IL-6 and IL-10 are significantly increased while HLADR expression is dramatically decreased in SAI patients. Moreover, these changes are detectable within $48 \mathrm{~h}$ after a stroke, which clearly precedes the time window of SAI occurrence [23]. As a result, IL-6, IL-10 and HLA-DR are good candidate biomarkers for the early detection of SAI. Furthermore, exploring the cellular mechanism underlying IL-6, IL-10 and HLA-DR release after stroke could pave the way towards preventing SAI.
Our previous study showed that stroke significantly stimulates sympathetic activation [24]. Moreover, the sympathetic pathway has been reported in multiple experimental studies to be the communication link between the neural and immune systems [15, 25]. Numerous clinical studies have even reported that stroke patients with high NA levels are at increased risk of SAI [16-17]. In this study, we observed that sympathetic pathway activation promotes an anti-inflammatory
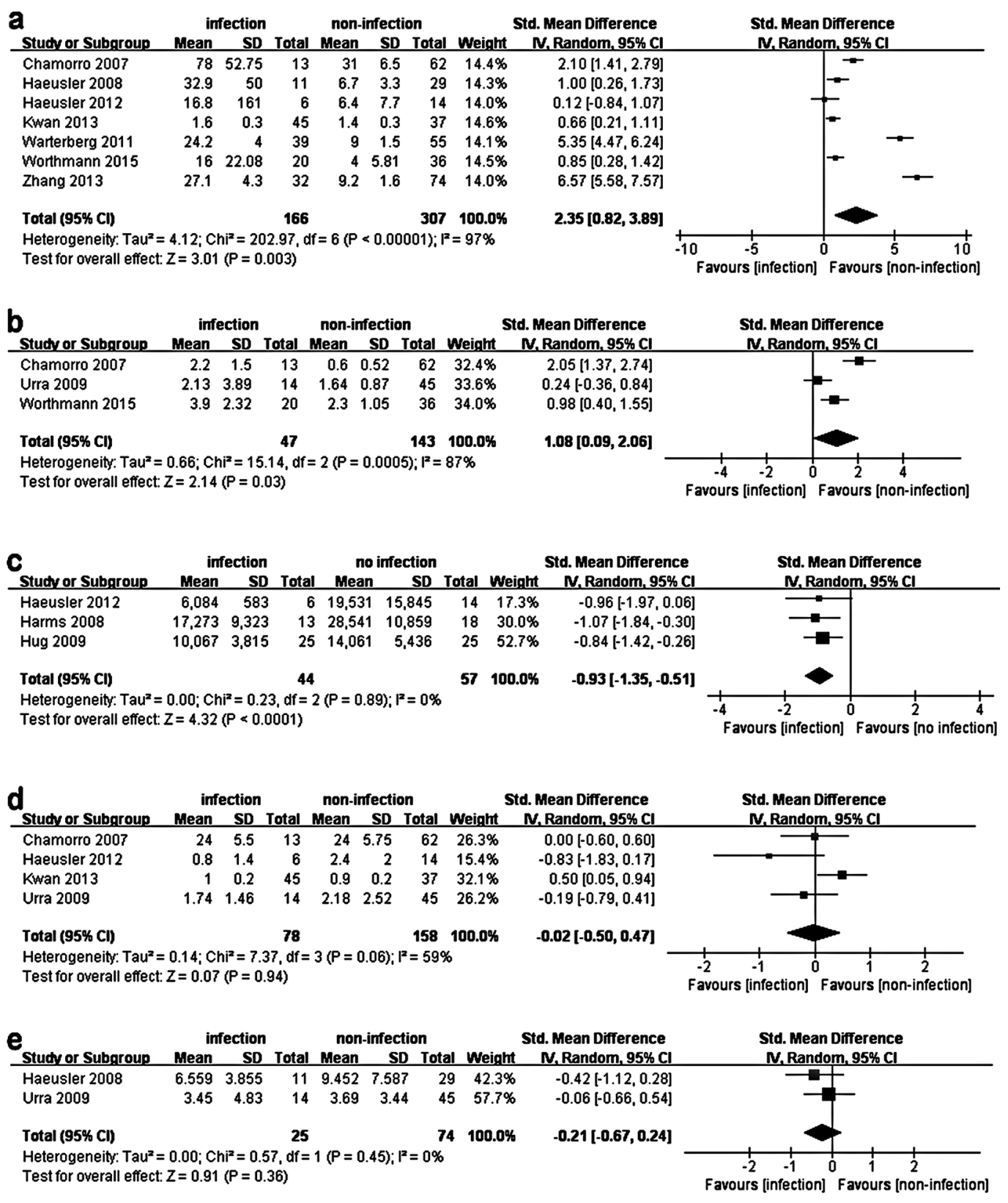

Figure 1: Pooled analysis of the difference in peripheral cytokine levels between SAI patients and no-infection stroke patients. The squares and horizontal lines correspond to the study-specific Std.MD and 95\%CI. The area of the squares reflects the weight. IV means inverse variance. Because of the significant heterogeneity, a random effects model was used to pool SMD for the included studies. SAI patients had significantly higher IL-6 (a. $\mathrm{P}=0.003$ ) and IL-10 (b. $\mathrm{P}=0.03$ ) levels compared to no-infection stroke patients within 48h after stroke onset. Moreover, a significantly lower HLA-DR level (c. $\mathrm{P}<0.0001)$ was found in SAI patients. However, TNF- $\alpha($ d. $\mathrm{P}=0.94)$ and IFN- $\gamma($ e. $\mathrm{P}=0.36)$ have no statistically significant difference between the two groups. 

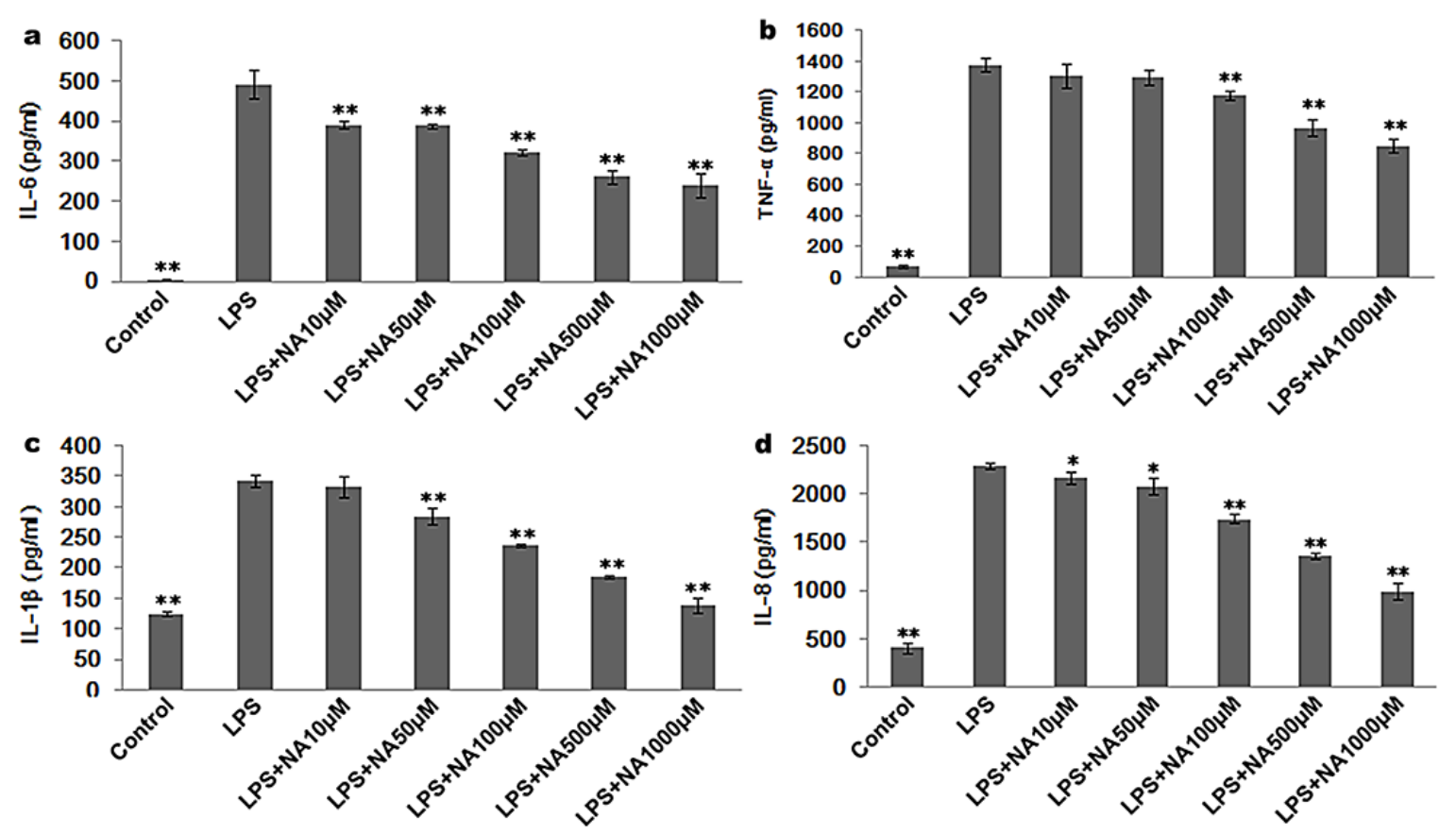

Figure 2: NA stimulation suppresses cytokine release induced by LPS in THP-1 cells. a. LPS-induced IL-6 was inhibited by NA in a dose-dependent manner. b. LPS-induced TNF- $\alpha$ release was decreased by NA at the minimum concentration of $100 \mu \mathrm{M}$, and a dose-dependent response was observed with concentration increases of $100 \mu \mathrm{M}$. c. LPS-induced IL-1 $\beta$ release was reduced by NA at the minimum concentration of $50 \mu \mathrm{M}$. A dose-dependent response was observed with concentration increases of $50 \mu \mathrm{M}$. d. LPS-induced IL-8 release was also reduced by NA in a dose-dependent manner. *, $\mathrm{P}<0.05$, and **, $\mathrm{P}<0.01$ compared to the LPS stimulation group.
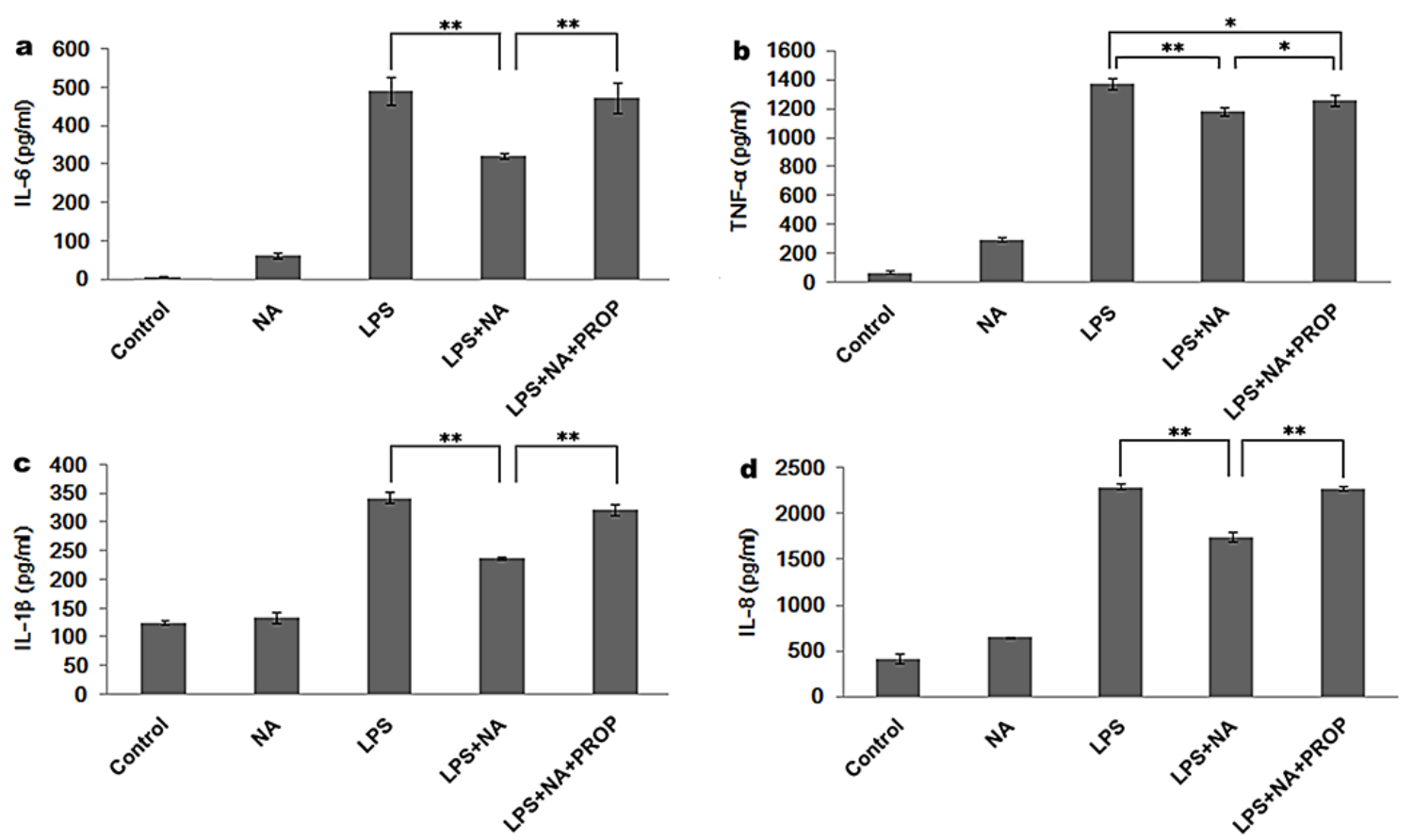

Figure 3: Propranolol reverses the cytokine release modulation of NA in THP-1 cells. As each cytokine was significantly suppressed by NA at the concentration of $100 \mu \mathrm{M}, 100 \mu \mathrm{M}$ NA was applied in the following study. NA inhibited LPS induced IL-6 (a) TNF- $\alpha$ (b) IL-1 $\beta$ (c) and IL-8 (d) release. However, propranolol stimulation could significantly reduce the inhibition effect of NA by increasing the release of IL-6 (a), TNF- $\alpha$ (b), IL-1 $\beta$ (c) and IL-8 (d). *, P $<0.05$, and **, P $<0.01$. 
drive in monocytes by inhibiting the NF- $\kappa \mathrm{B}$ pathway phosphorylation activity, involving not only HLA-DR and some pro-inflammatory cytokines inhibition but also increased IL-10 release. Unexpectedly, activation of the sympathetic pathway suppressed LPS-induced IL-6 release, which contradicts our pooled analysis findings of increased peripheral IL- 6 levels in SAI patients. These results suggest that activation of the sympathetic pathway partially account for the specific alteration of the peripheral immunological indicators observed in SAI patients.

Research has reported that HLA-DR reduction on monocytesis associated with an increased risk of infection [26]. HLA-DR expression reflects the status of global immune function due to its essential role in the process of antigen presentation [27]. In this study, we confirm that HLA-DR levels can discriminate between SAI patients and no-infection stroke patients before the time window of infection. We also for the first time show how the activation of the sympathetic pathway significantly decreases HLA-DR expression, and demonstrate how this effect can be reversed by propranolol. Accordingly, managing HLA-DR levels and sympathetic pathway activation with treatments such as propranolol in the clinic might be a potential approach for preventing SAI.
Although experimental studies have proven strokeinduced immunodepression by showing decreased peripheral IL-6 production, numerous clinical studies have found that IL- 6 expression actually increases after stroke in response to strong inflammatory reactions induced by ischaemic brain injury [28-30]. Our results suggest that very strong inflammatory responses occur in SAI patients which activate anti-inflammatory feedback causing increased IL-10. Previous studies support this connection to immune function by showing that stroke patients with large infarct size had strong immune responses and were more vulnerable to infection [31-32]. As a result, the immunological characteristics of SAI patients could be due to harmful consequences from anti-inflammatory feedback in the peripheral immune system, such as decreased HLA-DR and increased IL-10 levels.

In addition to the sympathetic pathway, the activation of other potential pathways such as the hypothalamicpituitary-adrenal (HPA) axis and the cholinergic pathway have been reported to mediate dysfunction in peripheral immune cells and increase susceptibility to infection in stroke patients [6,32-34]. These pathways seem to be important additive mechanisms for the development of SAI. Nevertheless, our findings strongly suggest that inhibition of sympathetic actions is an effective approach
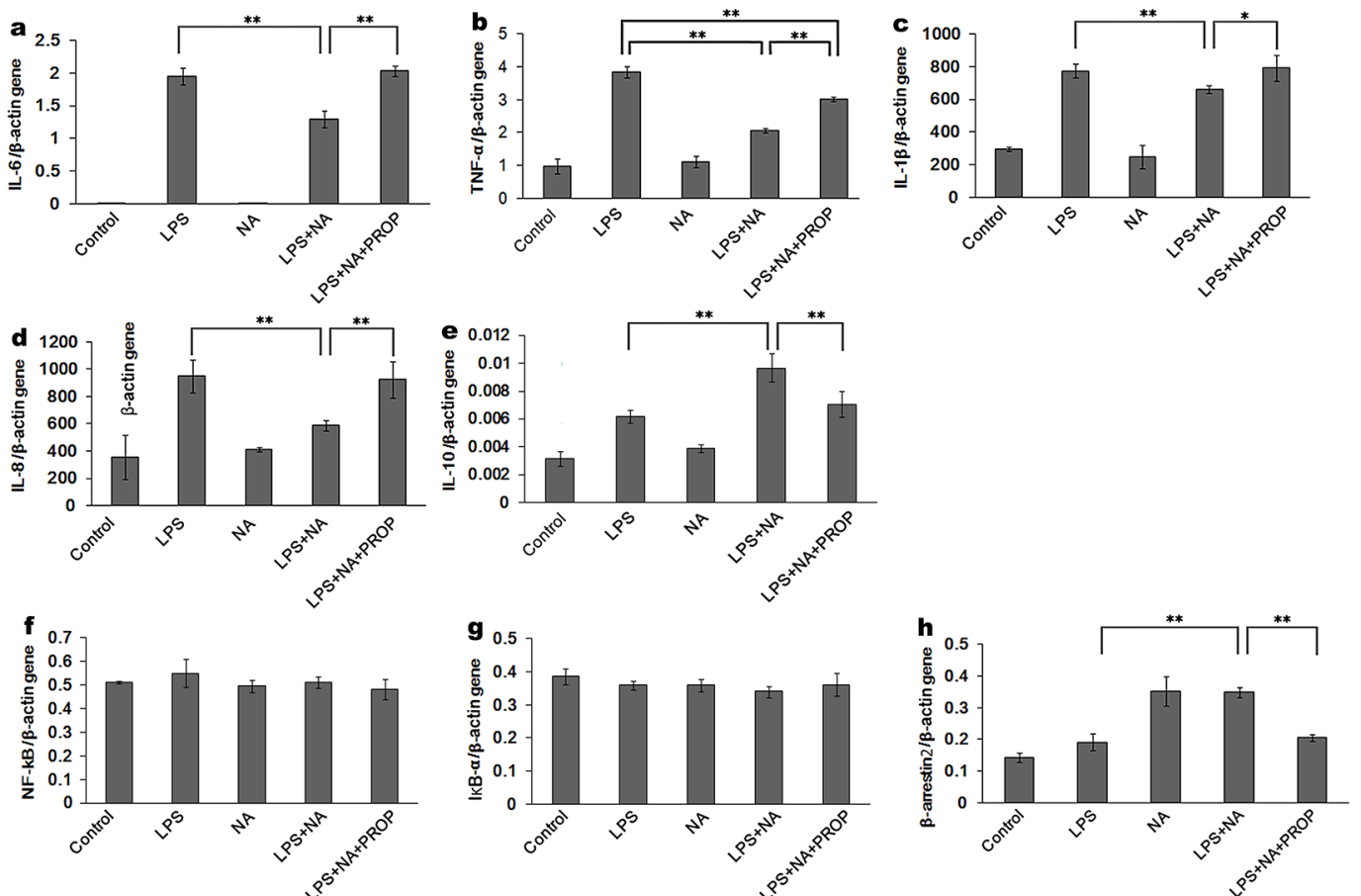

Figure 4: Effect of NA in THP-1 cells on cytokine expression detected at the gene level. LPS induced high IL-6 (a) TNF- $\alpha$ (b) IL-1 $\beta$ (c) and IL-8 (d) gene expression. With the co-stimulation of NA, the gene expression of these cytokines was significantly decreased (a-d). IL-10 gene expression in the LPS and NA co-stimulation groups were significantly increased compared to the LPS stimulation group (e) In the propranolol stimulation group, IL-6 (a), TNF- $\alpha$ (b), IL-1 $\beta$ (c) and IL-8 (d) gene expression were elevated whileIL-10 gene expression was decreased (e). NA stimulation could significantly increase $\beta$-arrestin2 gene expression (h) NF- $\kappa \mathrm{B}$ and I $\kappa \mathrm{B} \alpha$ gene expression were not affected in each group (f-g) *, $\mathrm{P}<0.05$, and **, $\mathrm{P}<0.01$. 
for reversing HLA-DR decrease and IL-10 increase in stroke patients, paving the way towards more effective therapies for SAI. Owing to limitations in the number of included studies and available data, the evidence level of the SAI-specific indicators is somewhat limited by publication and selection bias. Hence, large sample and multi-center clinical studies of the specific indicators for SAI are still needed in the future.
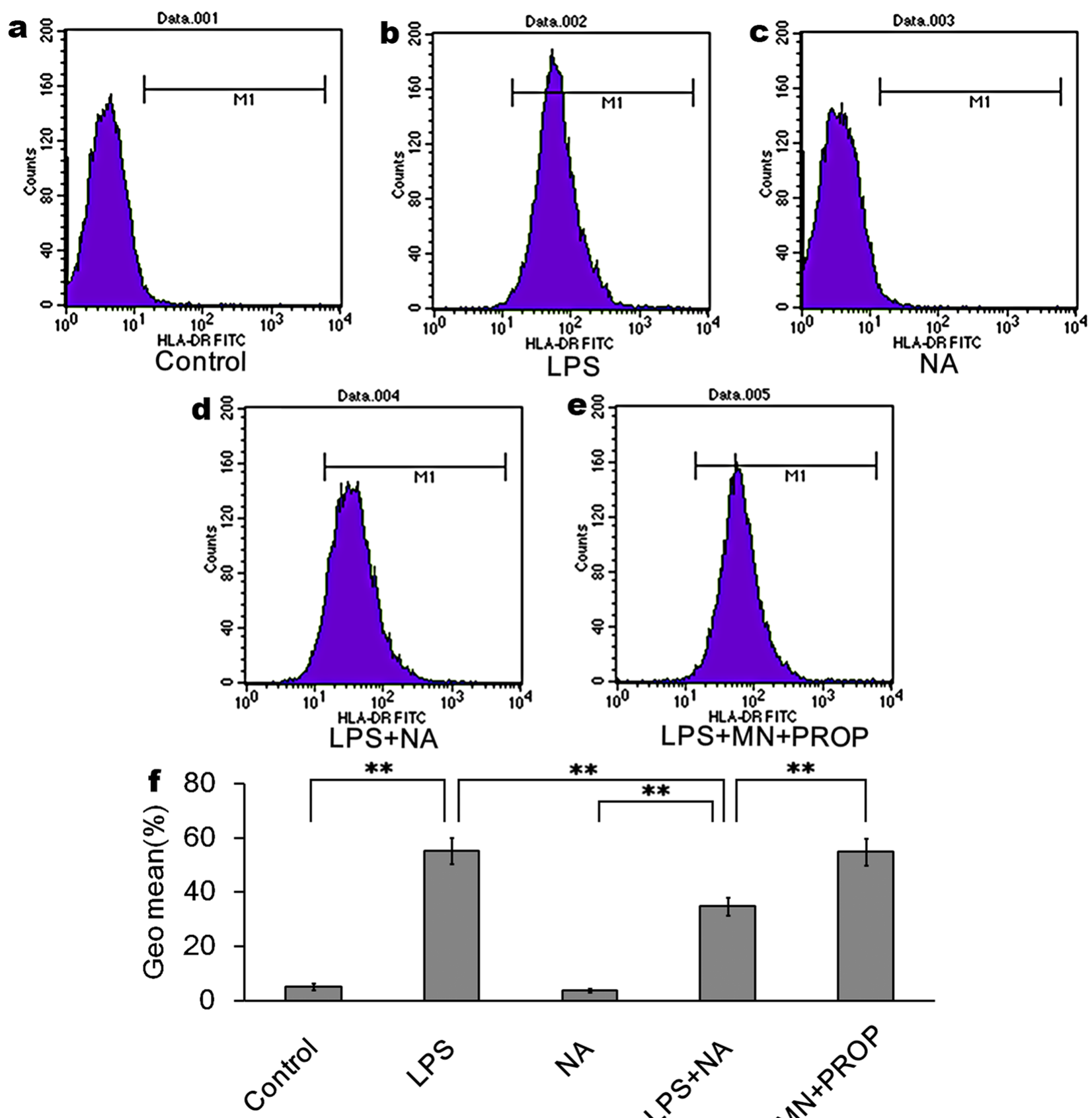

**

**

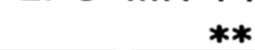




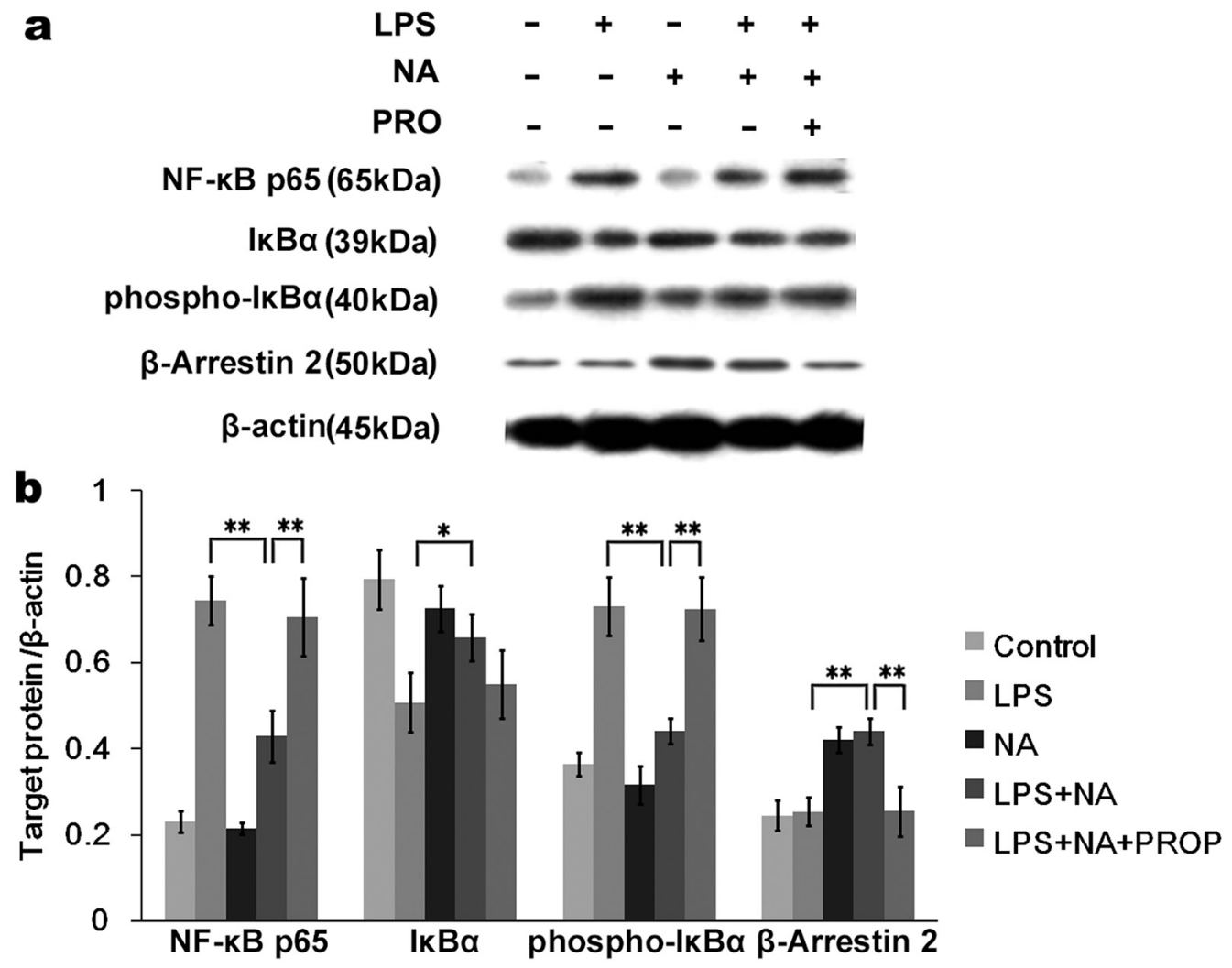

Figure 6: Activated $\beta$-arrestin2 by NA inhibits IкBa phosphorylation of $\mathbf{N F - \kappa B}$ pathway. a. The Western blot image

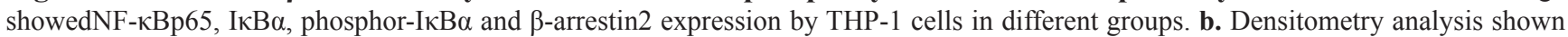
as graph bars for each protein expression level normalized with $\beta$-actin. LPS stimulation significantly activated the NF- $\mathrm{B}$ pathway by

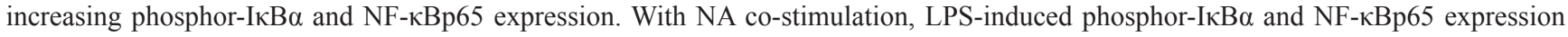
were significantly inhibited. Meanwhile, increased $\beta$-arrestin 2 and $\mathrm{I} \kappa \mathrm{B} \alpha$ expression were detected. In the propranolol stimulation group, $\beta$-arrestin2 was not significantly activated, resulting in increased phosphor-I $\kappa \mathrm{B} \alpha$ and NF- $\kappa \mathrm{B}$ p65 expression compared to the NA costimulation group. ${ }^{*}, \mathrm{P}<0.05$, and $* *, \mathrm{P}<0.01$.

\section{MATERIALS AND METHODS}

\section{Systematic review of clinical studies}

A systematic review of clinical studies was performed to demonstrate whether an immunological disorder might be the cause and pathogenesis of SAI by pooling the difference in immunological biomarker(s) levels within three days after stroke between SAI patients and patients without infection. Detailed procedures were made following the guideline of RevMan with the RevMan5.2 software (The Cochrane Collaboration, UK), consisting of a literature search and selection, data extraction, and analyses (Supplemental Data). The standard mean differences (SMD) were calculated to evaluate the differences.

\section{Cell culture}

To investigate the underlying mechanism behind the immunological changes in SAI, human THP-1 monocytes (the Cell Bank of National Academy of Sciences,
Shanghai, China) were applied in this study. Cells were cultured in RPMI1640 (Invitrogen) supplemented with $10 \%$ heat-inactivated $\mathrm{FBS}, 100 \mathrm{U} / \mathrm{mL}$ penicillin and $100 \mathrm{mg} / \mathrm{mL}$ streptomycin. Before the experimental procedure was performed, THP-1 cells were differentiated into macrophages with PMA $\left(1.28 \mathrm{uM}, 5^{*} 10^{\wedge} 5\right.$ cells $/ 24$ well plate) for $48 \mathrm{~h}$. All the cells were incubated at $37^{\circ} \mathrm{C}$ in a $5 \% \mathrm{CO}_{2}$ humidified incubator.

\section{Drug administration}

Lipopolysaccharide (LPS) was applied to stimulate THP-1 cells at the concentration of $50 \mathrm{ng} / \mathrm{ml}$ for $6 \mathrm{~h}$ to simulate sepsis [35-36]. To better understand the effect of the sympathetic neurotransmitter (norepinephrine, NA, Sigma-I6504, American) on THP1 cells, dose-response studies were conducted to detect cytokine levels after drug interventions at different concentrations (NA $10 \mu \mathrm{M}, 50 \mu \mathrm{M}, 100 \mu \mathrm{M}, 500 \mu \mathrm{M}$, $1000 \mu \mathrm{M}$ ). Additionally, propranolol (Sigma-P8688, America) was applied to reverse the sympathetic activation. 
Table 2: All antibodies applied in the western blot analysis

\begin{tabular}{|c|c|c|c|c|}
\hline Protein & Molecular weight & Source & Company & $\begin{array}{c}\text { Antibody } \\
\text { concentration }\end{array}$ \\
\hline NF-кB p65 & $65 \mathrm{kDa}$ & Rabbit & CST, USA & $1: 1500$ \\
\hline $\mathrm{I} \kappa \mathrm{B} \alpha$ & $39 \mathrm{kDa}$ & Rabbit & CST, USA & $1: 1500$ \\
\hline phospho-I $\kappa \mathrm{B} \alpha$ & $40 \mathrm{kDa}$ & Rabbit & CST, USA & $1: 1000$ \\
\hline$\beta$-Arrestin 2 & $50 \mathrm{kDa}$ & Rabbit & CST, USA & $1: 1000$ \\
\hline$\beta$-actin & $45 \mathrm{kDa}$ & Rabbit & CST, USA & $1: 3000$ \\
\hline Secondary antibodies & Anti-RabbitlgG(HRP) & Goat & Abcam, UK & $1: 3000$ \\
\hline
\end{tabular}

Table 3: All gene primer sequences (Generay Biotechnology, Shanghai, China) applied in the qPCR analysis

\begin{tabular}{|c|c|c|}
\hline Gene (GenBank) & & Primer sequence (5'-3') \\
\hline \multirow[t]{2}{*}{ IL-6 (NM_000600.3) } & Forward & CAGACAGCCACTCACCTC \\
\hline & Reverse & CTCAAACTCCAAAAGACCAG \\
\hline \multirow[t]{2}{*}{ IL-10 (NM_000572.2) } & Forward & GGAGAACCTGAAGACCCT \\
\hline & Reverse & TGATGAAGATGTCAAACTCACT \\
\hline \multirow[t]{2}{*}{ IL-1 $\beta$ (NM_000576.2) } & Forward & ACCACCACTACAGCAAGG \\
\hline & Reverse & AAAGATGAAGGGAAAGAAGG \\
\hline \multirow[t]{2}{*}{ IL-8(NM_000584.3) } & Forward & GCATAAAGACATACTCCAAACC \\
\hline & Reverse & АААСТТСТССАСААСССТСТ \\
\hline \multirow[t]{2}{*}{ TNF- $\alpha$ (NM_000594.3) } & Forward & TGTAGCAAACCCTCAAGC \\
\hline & Reverse & GGACCTGGGAGTAGATGAG \\
\hline \multirow[t]{2}{*}{ NF-кB (NM_001165412.1) } & Forward & CCACAAGCAAGAAGCTGAAG \\
\hline & Reverse & AGATACTATCTGTAAGTGAACC \\
\hline \multirow[t]{2}{*}{ IкB $\alpha$ (NM_020529.2) } & Forward & ACACTAGAAAACTTCAGATGC \\
\hline & Reverse & ACACAGTCATCATAGGGCAG \\
\hline \multirow[t]{2}{*}{ ARRB2 (NM_001257331.1) } & Forward & TGTGGACACCAACCTCATTG \\
\hline & Reverse & TCATAGTCGTCATCCTTCATC \\
\hline \multirow[t]{2}{*}{$\beta$-actin (NM_001101.3) } & Forward & GCACCACACCTTCTACAATGAG \\
\hline & Reverse & ATAGCACAGCCTGGATAGCAAC \\
\hline
\end{tabular}

\section{Cytokine measurement by ELISA assays}

Concentrations of inflammatory cytokines (IL6 , TNF- $\alpha$, IL-1 $\beta$, IL-8 and IL-10) secreted by THP1 macrophages were detected using ELISA kits (JoyeeBiotechnics Co. Ltd, Shanghai, China) according to the manufacturer's instructions.

\section{HLA-DR detection by flow cytometry}

The FITC anti-human HLA-DR was purchased from Biolegend (CA, USA). The expression of HLA-DR was determined by flow cytometry (FACScan, BD Bioscience) according to the manufacturer's instructions. The values were expressed as mean fluorescence intensity (MFI). Data analysis was performed using CellQuest software (BD Bioscience, Franklin Lakes, NJ, USA).

\section{Protein extraction and western blot analysis}

After drug stimulation, THP-1 cells were concentrated and washed three times in cold PBS. Protein extraction was obtained by lysing the cells in $300 \mu \mathrm{L}$ RIPA lysis buffer with $3 \mu \mathrm{L}$ PMSF and $3 \mu \mathrm{L}$ protease 
inhibitor (Abcam, Cambridge, England). Then, protein concentrations were measured using the BCA protein assay (Beyotime, Shanghai, China). Equal amounts of proteins $(20 \mu \mathrm{g})$ were electrophoresed in an SDS-PAGE with $8 \%$ $10 \%$ polyacrylamide gel, and then transferred to a PVDF membrane (Merck Millipore, Billerica, MA, USA). After that, the membranes were blocked with $5 \%$ nonfat milk in TBST and then immunoblotted overnight at $4{ }^{\circ} \mathrm{C}$ with primary antibodies (Table 2). Subsequently, the membranes were washed with TBST three times and incubated with the secondary antibody (Table 2). Finally, the membranes were visualized using chemiluminescence (Amersham, Uppsala, Sweden) and immunoreactivity analysis was performed by an imaging system (Peiqing JS-780, Shanghai, China).

\section{RNA extraction and RT-qPCR analysis}

After drug stimulation, the total RNA of each group was extracted using the Trizol Reagent (Invitrogen, Carlsbad, CA, USA) following the manufacturer's instructions. Then, complementary DNA synthesis was performed using the Hiscript 1st strand cDNA synthesis kit (Vazyme, Nanjing, China) by PCR (Eppendorf, Hamburg, Germany). Subsequently, RT-qPCR was performed using AceQ $^{\mathrm{TM}}$ qPCR SYBR Green Master Mix (Vazyme) in accordance with the manufacturer's protocol on the StepOnePlus ${ }^{\text {TM }}$ Real-Time PCR system (ThermoFisher Scientific, USA). Primer sequences for each aim gene are shown in Table 3 . The results were expressed as the number of target gene copies per 35 copies.

\section{Statistical analysis}

Every experiment was performed in triplicate. The results were expressed as means \pm standard deviations, and statistically analyzed through one-way analysis of variance (ANOVA) and Student's t-tests. $\mathrm{P}<0.05$ was considered to be statistically significant. All statistical analyses were performed using SPSS 17.0 (Statistical Package for the Social Science, SPSS Ins., IL, USA).

\section{CONCLUSION}

Peripheral IL-6, IL-10 and HLA-DR are good candidate biomarkers for the early detection of SAI. The activation of the sympathetic pathway could partly explain the specific alteration of the immunological characteristics observed in SAI patients, resulting in a decreasing HLADR level and increasing IL-10 level. However, the cellular mechanism underlying IL-6 release in SAI patients needs further exploration.

\section{ACKNOWLEDGMENTS}

This work was supported by grants from the National Natural Science Foundation of China (Number
81271336, FY) and the Fundamental Research Funds for the Central Universities (KYLX15_0183). The funders had no role in study design, data collection and analysis, decision to publish, or preparation of the manuscript.

\section{CONFLICTS OF INTEREST}

The authors declare that there is no conflict of interest.

The authors confirm that neither the submitted manuscript nor any similar manuscript, in whole or in part, is under consideration, in press, published, or reported elsewhere.

\section{REFERENCES}

1. Emsley HC, Hopkins SJ. Acute ischaemic stroke and infection: recent and emerging concepts. Lancet Neurol. 2008. 7:341-53.

2. Westendorp WF, Nederkoorn PJ, Vermeij JD, Dijkgraaf MG and Beek, DVD. Post-stroke infection: a systematic review and meta-analysis. BMC Neurol. 2011. 11:110.

3. Kwan J, Pickering RM, Kunkel D, Fitton C, Jenkinson D, Perry VH, Ashburn AM. Impact of stroke-associated infection on long-term survival: a cohort study. J NeurolNeurosurg Psychiatry. 2013. 84:297-304.

4. Brogan E, Langdon C, Brookes K, Budgeon C and Blacker D. Respiratory Infections in Acute Stroke: Nasogastric Tubes and Immobility areStronger Predictors than Dysphagia. Dysphagia. 2014.29:340-5.

5. Westendorp WF, Vermeij JD, Zock E, Hooijenga IJ, Kruyt ND, Bosboom HJ, Kwa VI, Weisfelt M, Remmers MJ, ten Houten R, Schreuder AH, Vermeer SE, van Dijk EJ, et al. ThePreventive Antibiotics in Stroke Study (PASS): a pragmatic random open-label masked endpoint clinical trial. Lancet. 2015. 385:1519-26.

6. Angel Chamorro, Andreas M, Planas AM, Xabier U, Diederik VDB and Roland V. The immunology of acute stroke. Nat Rev Neurol. 2012.8:401-10.

7. Dirnagl U, Klehmet J, Braun JS, Harms H, Meisel C, Ziemssen T, Prass K, Meisel A. Stroke-induced immunodepression: experimental evidence and clinical relevance. Stroke. 2007. 38:770-3.

8. Kwan J, Horsfield G, Bryant T, Gawne-Cain M, Durward G, Byrne CD, Englyst NA. IL-6 is a predictive biomarker for stroke associated infection and future mortality in the elderly after an ischemic stroke. ExpGerontol. 2013. 48:960-5.

9. Bustamante A, Sobrino T, Giralt D, García-Berrocoso T, Llombart V, Ugarriza I, Espadaler M, Rodríguez N, Sudlow C, Castellanos M, Smith CJ, Rodríguez-Yánez M, WajeAndreassen U, et al. Prognostic value of blood interleukin-6 in the prediction of functional outcome after stroke: a systematic review and meta-analysis. J Neuroimmunol. 2014. 274:215-24. 
10. Chen G Y, Nuñez, G. Sterile inflammation: sensing and reacting to damage. Nat Rev Immunol. 2010. 10:826-37.

11. Worthmann H, Tryc AB, Dirks M, Schuppner R, Brand $\mathrm{K}$, Klawonn F, Lichtinghagen $\mathrm{R}$, Weissenborn $\mathrm{K}$. Lipopolysaccharide binding protein, interleukin-10, interleukin-6 and C-reactive protein blood levels in acute ischemic stroke patients with post-stroke infection. J Neuroinflammation. 2015. 12:13.

12. Whiteley W, Wardlaw J, Dennis M, Lowe G, Rumley A, Sattar N, Welsh P, Green A, Andrews M, Sandercock P. The use of blood biomarkers to predict poor outcome after acute transient ischemic attack or ischemic stroke. Stroke. 2012. 43:86-91.

13. Haeusler KG, Schmidt WU, Foehring F, Meisel C, Guenther C, Brunecker P, Kunze C, Helms T, Dirnagl U, Volk HD, Villringer A. Immune responses after acute ischemic stroke or myocardial infarction. Int J Cardiol. 2012. 155:372-7.

14. Walter U, Kolbaske S, Patejdl R, Steinhagen V, AbuMugheisib M, Grossmann A, Zingler C, Benecke R. Insular stroke is associated with acute sympathetic hyperactivation and immunodepression. Eur J Neurol. 2013. 20:153-9.

15. HannawiY, Hannawi B, Rao CP, Suarez JI, Bershad EM. Stroke-Associated Pneumonia: Major Advances and Obstacles. Cerebrovasc Dis. 2013, 35:430-3.

16. Chamorro A, Amaro S, Vargas M, Obach V, Cervera A, Gómez-Choco M, Torres F, Planas AM. Catecholamines, infection, and death in acute ischemic stroke. J Neurol Sci. 2007. 252:29-35.

17. Urra X, Cervera A, Obach V, Climent N, Planas AM, Chamorro A. Monocytes are major players in the prognosis and risk of infection after acute stroke. Stroke. 2009. 40:1262-8.

18. Kenji Watari, Michio Nakaya, Motohiro Nishida, KyeongMan Kim, Hitoshi Kurose. $\beta$-arrestin2 in Infiltrated Macrophages Inhibits Excessive Inflammation after Myocardial Infarction. Plos One. 2013, 8.

19. Luan B, Zhang Z, Wu Y, Kang J, Pei G. $\beta$-Arrestin2 functions as a phosphorylation-regulated suppressor of UV-induced NF- $\kappa B$ activation. Embo J. 2005. 24:4237-46.

20. Tang JR, Michaelis KA, Nozik-Grayck E, Seedorf GJ, Hartman-Filson M, Abman SH, Wright CJ. The NF-kB inhibitory proteins $\mathrm{I} \kappa \mathrm{B} \alpha$ and $\mathrm{I} \kappa \mathrm{B} \beta$ mediate disparate responses to inflammation in fetal pulmonary endothelial cells. J Immunol. 2013. 190:2913-23.

21. Prass K, Meisel C, Hoflich C, Braun J, Halle E, Wolf T, Ruscher K, Victorov IV, Priller J, Dirnagl U, Volk HD, Meisel A. Stroke-induced immunodeficiency promotes spontaneous bacterial infections and is mediated by sympathetic activation reversal by poststroke $\mathrm{T}$ helper cell type 1-like immunostimulation. J Exp Med. 2003. 198:725-36.

22. Prass K, Braun JS, Dirnagl U, Meisel C, Meisel A. Stroke propagates bacterial aspiration to pneumonia in a model of cerebral ischemia. Stroke. 2006. 37:2607-12.
23. Haeusler KG, Schmidt WU, Fohring F, Meisel C, Helms $\mathrm{T}$, Jungehulsing GJ, Nolte $\mathrm{CH}$, Schmolke $\mathrm{K}$, Wegner B, Meisel A, Dirnagl U, Villringer A, Volk HD. Cellular immunodepression preceding infectious complications after acute ischemic stroke in humans. Cerebrovasc Dis. 2008. 25:50-8.

24. Yan FL, Zhang JH. Role of the sympathetic nervous system and spleen in experimental stroke-induced immunodepression. Med Sci Monit. 2014. 20:2489-96.

25. Winklewski PJ, Radkowski M, Demkow U. Crosstalk between the inflammatory response, sympathetic activation and pulmonary infection in the ischemic stroke. $\mathrm{J}$ Neuroinflammation. 2014. 11:2-2.

26. Lekkou A, Karakantza M, Mouzaki A, Kalfarentzos F, Gogos CA. Cytokineproduction and monocyte HLA-DR expression as predictors ofoutcome for patients with community-acquired severe infections. Clin Diagn Lab Immunol. 2004. 11:161-7.

27. Kim OY, Monsel A, Bertrand M, Coriat P, Cavaillon JM, Adib-Conquy M. Differential down-regulation of HLA-DR on monocyte subpopulations during systemic inflammation. Crit Care. 2010. 14:243-4.

28. Scheibe F, Ladhoff J, Huck J, Grohmann M, Blazej K, Oersal A, Baeva N, Seifert M, Priller J. Immune effects of mesenchymal stromal cells in experimental stroke. J Cereb Blood Flow Metab. 2012. 32:1578-88.

29. Kate Lykke L, Knut B, Bente F. Inflammatory cytokines in experimental and human stroke. J Cereb Blood Flow Metab. 2012. 32:1677-98.

30. Engel O, Akyüz L, da Costa Goncalves AC, Winek K, Dames C, Thielke M, Herold S, Böttcher C, Priller J, Volk HD, Dirnagl U, Meisel C, Meisel A. Cholinergic Pathway Suppresses Pulmonary Innate Immunity Facilitating Pneumonia After Stroke. Stroke. 2015. 46.

31. An C, Shi Y, Li P, Hu X, Gan Y, Stetler RA, Leak RK, Gao Y, Sun BL, Zheng P, Chen J. Molecular dialogs between the ischemic brain and the peripheral immune system: Dualistic roles in injury and repair. Prog Neurobiol. 2013. 115:6-24.

32. Liesz A, Hagmann S, Zschoche C, Adamek J, Zhou W, Sun L, Hug A, Zorn M, Dalpke A, Nawroth P, Veltkamp R. The Spectrum of systemic immune alterations after murine focal ischemia: immunodepression versus immunomodulation. Stroke. 2009. 40:2849-58.

33. Engel O, Akyuz L, da Costa Gonacalves AC, Winek K, Dames C, Thielke M, Herold S, Bottcher C, Priller C, Volk HD, Dirnaql U, Meisel C, et al. Cholinergic Pathway Suppresses Pulmonary Innate Immunity Facilitating Pneumonia After Stroke. Stroke. 2015. 46:3232-40.

34. Emsley HC, Smith CJ, Gavin CM, Georgiou RF, Vail A, Barberan EM, Illingworth K, Scarth S, Wickramasinghe V, Hoadley ME, Rothwell NJ, Tyrrell PJ, Hopkins SJ. Clinical outcome following acute ischaemic stroke relates to both activation and autoregulatory inhibition of cytokine production. BMC Neurol. 2007; 7:5. 
35. Doll D N, Hu H, Sun J, Lewis SE, Simpkins JW, Ren X. Mitochondrial crisis in cerebrovascular endothelial cells opens the blood-brain barrier. Stroke. 2015. 46. 2015; 46:1681-9. doi: 10.1161/STROKEAHA.115.009099.

36. Mccoll BW, Rothwell NJ, Allan SM. Systemic inflammatory stimulus potentiates the acute phase and CXC chemokine responses to experimental stroke and exacerbates brain damage via interleukin-1 and neutrophildependent mechanisms. J Neurosci. 2007. 27:4403-12.

37. Hug A, Dalpke A, Wieczorek N, Giese T, Lorenz A, Auffarth G, Liesz A, Veltkamp R. Infarct volume is a major determiner of post-stroke immune cell function and susceptibility to infection. Stroke. 2009. 40:3226-32.
38. Harms H, Prass K, Meisel C, Klehmet J, Rogge W, Drenckhahn C, Göhler J, Bereswill S, Göbel U, Wernecke KD, Wolf T, Arnold G, Halle EV, et al. Preventive antibacterial therapy in acute ischemic stroke: a randomized controlled trial. Plos One. 2008. 3:e2158.

39. Wartenberg KE, Stoll A, Funk A, Meyer A, Schmidt JM, Berrouschot J. Infection after acute ischemic stroke: risk factors, biomarkers, and outcome. Stroke Res Treat. 2011. 2011:830614.

40. Zhang H, Li X. Correlation between inflammatory factors and post-stroke pneumonia in diabetic patients. Exp Ther Med. 2013. 6:105-108. 